\title{
ANCA Associated Vasculitis Secondary to Levamisole-Adultered Cocaine with Associated Membranous Nephropathy: A Case Series
}

\author{
David Collister $^{a, b} \quad$ Christie Sathianathan ${ }^{a, b} \quad$ Krista Ryz $^{a, b} \quad$ Martin Karpinski ${ }^{a, b}$ \\ Keevin Bernstein ${ }^{a, b}$ Ian W. Gibson ${ }^{c}$ \\ ${ }^{a}$ Department of Medicine, and ${ }^{\mathrm{b}}$ Section of Nephrology, University of Manitoba, and ${ }^{\mathrm{C}}$ Department of Pathology, \\ Health Sciences Center, Winnipeg, MB, Canada
}

\section{Keywords}

Levamisole-adultered cocaine - ANCA associated vasculitis · Membranous nephropathy

\begin{abstract}
Background: Cocaine is a risk factor for acute kidney injury and chronic kidney disease with progression to end-stage renal disease. Levamisole is an adulterant that is added to cocaine to enhance its euphoric effects. Levamisole-adulterated cocaine (LAC) is associated with the distinct clinical syndromes of agranulocytosis, leukocytoclastic vasculitis, cocaine-induced midline destructive lesions (CIMDL), and ANCA-associated vasculitis (AAV) with pauci-immune necrotizing glomerulonephritis. Methods: We reviewed all cases of AAV secondary to LAC at our institution. Results: We report 3 cases of AAV secondary to LAC and associated membranous nephropathy (MN). The first and second cases are concurrent AAV secondary to $L A C$ and associated MN while the third case involves the development of MN after AAV secondary to LAC. Conclusions: Clinicians should be aware of this novel association of LAC with MN.

(c) 2017 S. Karger AG, Basel
\end{abstract}

\section{Background}

Cocaine is associated with a variety of renal manifestations including hyponatremia [1], hypertension (HTN) [2], rhabdomyolysis [3], thrombotic microangiopathy (TMA) [4], renal infarction [5], renal vein thrombosis [6], acute interstitial nephritis [7], AA amyloidosis [8], arteriosclerosis [9-11], chronic kidney disease [12-14], and end-stage renal disease (ESRD) [15]. Levamisole is a common adulterant that is added to cocaine to potentiate its euphoric effects [16-18] and is associated with distinct clinical syndromes including agranulocytosis [19], leukocytoclastic vasculitis (LCV) [20], cocaine-induced midline destructive lesions [21], and ANCA-associated vasculitis (AAV) with pauci-immune necrotizing glomerulonephritis (GN) [22]. AAV is associated with membranous nephropathy $(\mathrm{MN})$ and $\mathrm{MN}$ is associated with crescents outside the setting of levamisole. We report our experience with 3 patients with AAV secondary to levamisole-adulterated cocaine (LAC) with associated MN.

\section{KARGER}

(C) 2017 S. Karger AG, Basel

E-Mail karger@karger.com

www.karger.com/ajn
Dr. David Collister

Seven Oaks General Hospital Renal Program

2300 McPhillips Street, 2PD13

Winnipeg, MB R2V 3M3 (Canada)

E-Mail dtcollister@gmail.com 

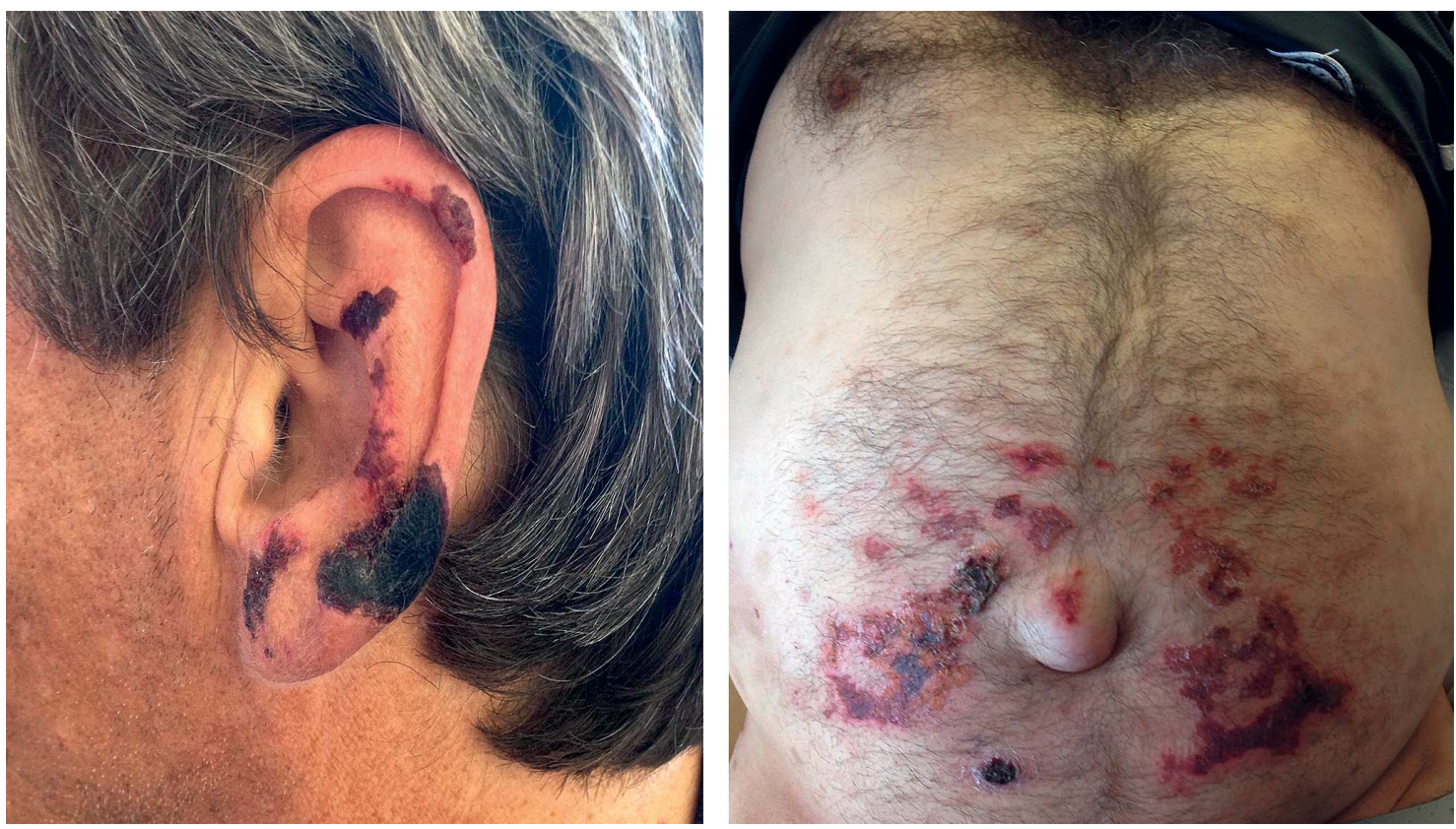

Fig. 1. Cutaneous manifestations of case 1 .

\section{Case Presentations}

\section{Case 1}

A 53-year-old Caucasian male with HTN, dyslipidemia, remote lumbar surgery, and a chronic pain syndrome was seen in the outpatient Nephrology clinic May 2014 with a 2 weeks history of lower extremity rash, hematuria, and a creatinine (Cr) of $150 \mu \mathrm{mol} / \mathrm{L}$. Medications included prednisone $100 \mathrm{mg}$ p.o. daily, rabeprazole $20 \mathrm{mg}$ p.o. daily, and occasional ibuprofen. He smoked 1 pack of cigarettes per day, had a remote history of alcohol abuse, and was actively using crack cocaine up to the day prior to his clinic visit. He denied any other illicit drug use. On physical examination, blood pressure (BP) was 144/100 $\mathrm{mm} \mathrm{Hg}$ with otherwise normal vitals. There were palpable purpura on his abdomen, thighs, and legs bilaterally (Fig. 1) as well as bilateral ear necrosis (Fig. 1). Relevant investigations are provided in Table 1.

A presumptive diagnosis of LAC-induced AAV was made and methylprednisolone $1 \mathrm{~g}$ IV q24h was initiated prior to renal biopsy (Fig. 2). The 34 glomeruli sampled for light microscopy (LM) showed an active focal crescentic and necrotizing GN with 4 glomeruli having active crescentic injury, 1 with segmental fibrinoid necrosis. There was also diffuse glomerular capillary wall thickening with epimembranous spikes seen on period acid methenamine stain. There was tubular epithelial injury with regeneration. Arteries sampled showed no active vasculitis. Immunofluorescence (IF) showed glomerular granular capillary loop IgG (2+), C3 (1+), kappa $(2+)$, and lambda (3+). Glomeruli were negative for $\operatorname{IgA}, \operatorname{IgM}$, $\mathrm{C} 1 \mathrm{q}$, and fibrinogen. Staining for anti-phospholipase A2 receptor (anti-PLA2R) was negative in the glomerular deposits [23]. Electron microscopy (EM) of 2 glomeruli showed diffuse epithelial cell foot process effacement, and numerous subepithelial electron dense immune complex deposits. No mesangial deposits were identified. Plasmapheresis was not performed. He was discharged with a prescription for prednisone $80 \mathrm{mg}$ p.o. daily $(1 \mathrm{mg} / \mathrm{kg})$ with tapering and perindopril $4 \mathrm{mg}$ p.o. daily. At the last follow-up of September 2015, Cr was $150 \mu \mathrm{mol} / \mathrm{L}$, estimated glomerular filtration rate (eGFR) $50 \mathrm{~mL} / \mathrm{min} / 1.73 \mathrm{~m}^{2}$, and urine protein to Cr ratio (PCR) $160 \mathrm{mg} / \mathrm{mmol}$ with ongoing crack cocaine use.

\section{Case 2}

A 35-year-old Caucasian male with a 1 week history of distal symmetric polyarthritis presented to his family physician in rural Manitoba, Canada, March 2013 and was prescribed prednisone 50 mg p.o. daily. Two days later, he presented to the emergency room with hemoptysis and iron deficiency anemia requiring blood transfusions. Computed tomography of his chest showed bilateral ground glass opacifications. Further history revealed chronic epistaxis for the last year. His Cr was $150 \mu \mathrm{mol} / \mathrm{L}$, and urine PCR was $593.2 \mathrm{mg} / \mathrm{mmol}$. A diagnosis of pulmonary renal syndrome (PRS) was made, and he was transferred to our tertiary center. He smoked half a pack of cigarettes and $4 \mathrm{~g}$ of marijuana per day, consumed 30 beers per week, and later disclosed intranasal cocaine and inhaled crack use. On physical examination, vitals were unremarkable and no abnormalities were noted including lymphadenopathy, mouth ulcers, uveitis, Raynaud's phenomenon, rashes, active joints, or neurologic symptoms. Relevant investigations are provided in Table 1.

A diagnosis of PRS secondary to LAC-induced AAV was made and a renal biopsy was performed (Fig. 2). There were 23 glomeruli for LM, up to 9 showing active segmental fibrinoid necrosis, and 3 with active crescentic injury. There was tubular epithelial injury with regeneration. Arteries sampled showed no active vasculitis. IF showed glomerular mesangial and capillary loop IgG $(1-2+)$, IgM (1+), C3 (1+), trace C1q, and lambda (1+). Glomeru- 


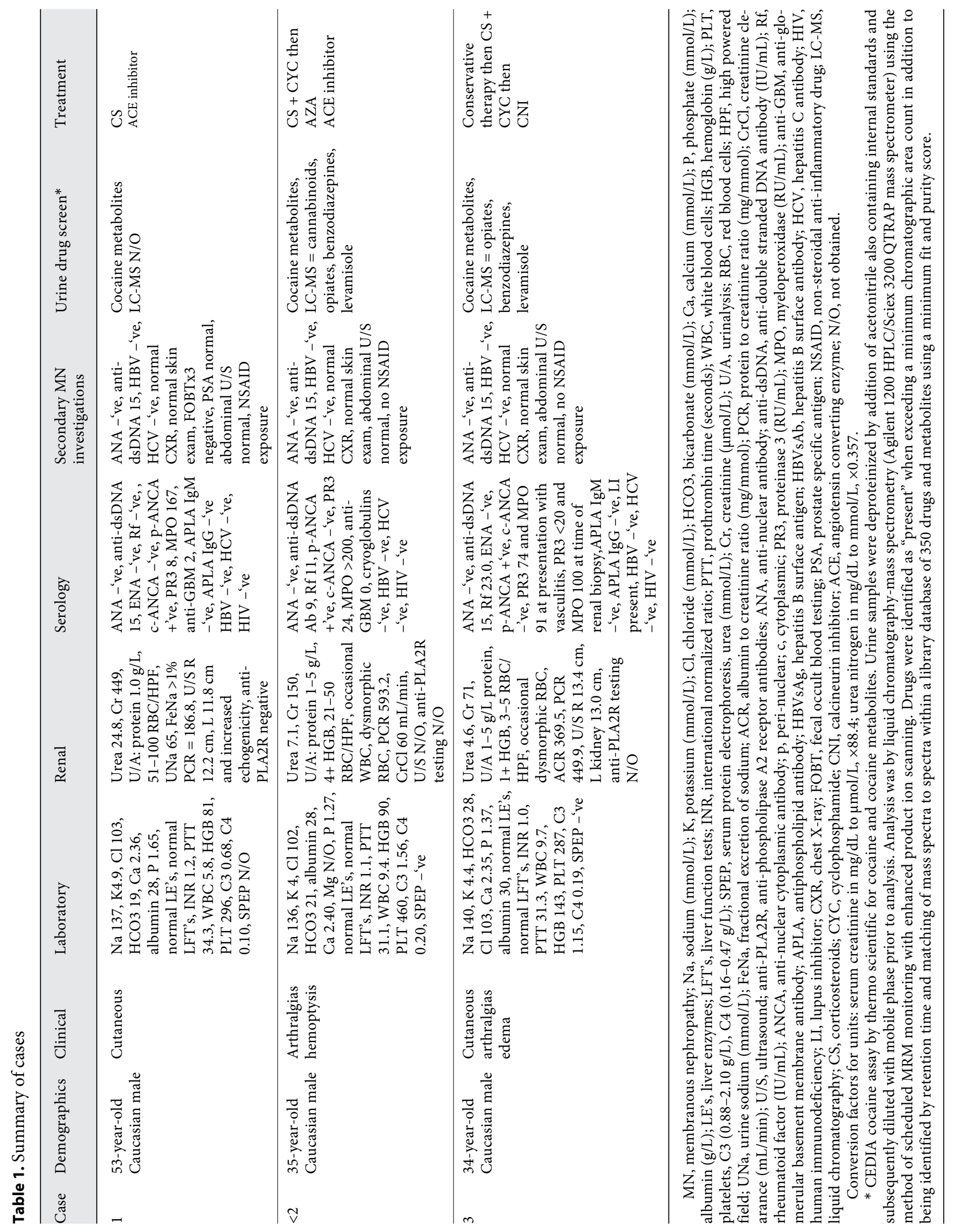



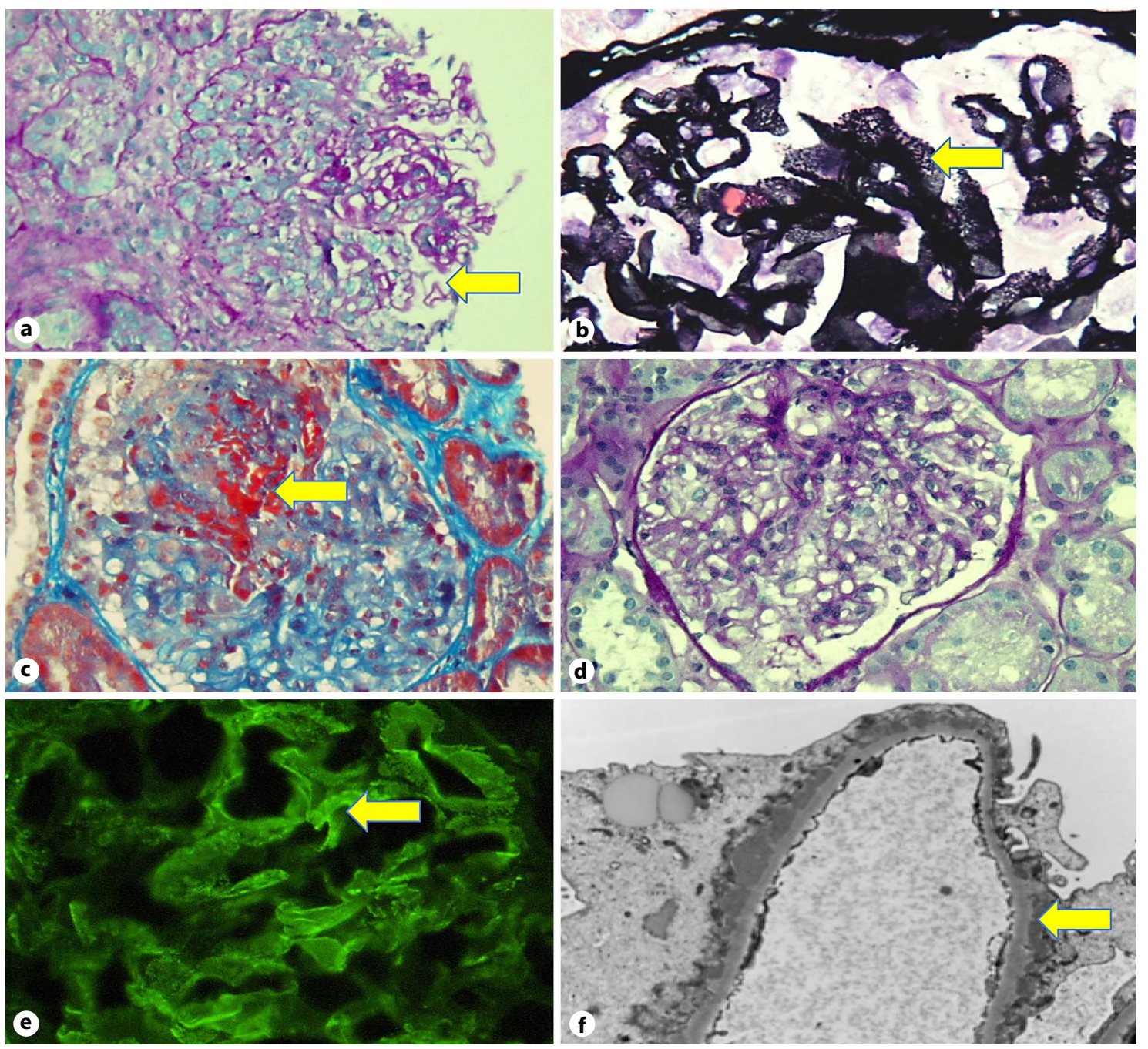

Fig. 2. Renal pathology. a Case 1 light microscopy PAS stain showing active crescent injury. $\mathbf{b}$ Case 1 light microscopy period acid methamine stain showing diffuse capillary wall thickening with epimembranous spikes. c Case 2 light microscopy trichrome stain showing segmental fibrinoid necrosis. d Case 3 light microscopy

li were negative for IgA, fibrinogen, and kappa. EM of 1 glomerulus showed diffuse epithelial cell foot process effacement and subepithelial and intramembranous immune complex deposits, with no mesangial deposits identified.

Based on the history of alveolar hemorrhage, prednisone $40 \mathrm{mg}$ p.o. b.i.d. (1 mg/kg) and cyclophosphamide (CYC) $1 \mathrm{~g} \mathrm{IV} \mathrm{admin-}$ istration were started. No plasmapheresis was performed. He received induction therapy with CYC $750 \mathrm{mg}$ IV q monthly for 6 months with corticosteroids followed by maintenance therapy with azathioprine (AZA) $100 \mathrm{mg}$ p.o. daily (which he did not tolerate) with prednisone tapering and subsequent discontinuation May 2014. At his last clinic follow-up in June 2014, his Cr was 121 $\mu \mathrm{mol} / \mathrm{L}$, eGFR $59 \mathrm{~mL} / \mathrm{min} / 1.73 \mathrm{~m}^{2}$, albumin to Cr ratio $62.9 \mathrm{mg} /$ $\mathrm{mmol}$, MPO $91 \mathrm{IU} / \mathrm{ml}$ with enalapril $10 \mathrm{mg}$ p.o. daily. He has been lost to follow-up.
PAS stain showing no significant abnormality. e Case 3 immunofluorescence showing granular capillary IgG staining. $f$ Case 3 electron microscopy showing diffuse podocyte effacement, subepithelial electron dense deposits, spikes of glomerular basement membrane.

\section{Case 3}

A 34-year-old Caucasian male with a history of LCV secondary to LAC-induced AAV in December 2010 treated with prednisone and AZA was referred to the outpatient Nephrology clinic in December 2011 for new onset proteinuria at a routine Rheumatology clinic visit. He had been feeling well other than fatigue and arthralgias. He did not have any new skin manifestations and was considered to be in AAV remission. Medications included AZA $150 \mathrm{mg}$ p.o. daily, ramipril $5 \mathrm{mg}$ p.o. daily, and acetaminophen p.r.n. He drank socially, was a lifelong non-smoker, "dabbled" in cocaine (denied recent use) but had no other illicit drug use. On physical examination, he was hypertensive with a BP of $167 / 81 \mathrm{~mm} \mathrm{Hg}$ and morbidly obese. Examination was unremarkable other than diffusely tender joints, trace edema, and hyper-pigmented lesions consistent with healed LCV on his extremities. Relevant investigations are provided in Table 1. 
A renal biopsy showed 15 glomeruli for LM, none were globally or segmentally sclerosed. There was no glomerular crescentic or necrotizing injury. Glomerular capillary walls appeared of normal thickness. Arteries showed no active vasculitis. IF showed glomerular granular capillary loop IgG $(3+), C 3(2+)$, trace kappa, lambda (3+), and mesangial IgM (1+). Glomeruli were negative for IgA, C1q, and fibrinogen. EM of 3 glomeruli showed scattered subepithelial immune complex deposits showing no specific substructure, with focal intervening spikes of new basement membrane material. No mesangial deposits were identified.

Conservative therapy for secondary $\mathrm{MN}$ was pursued with irbesartan titrated to $150 \mathrm{mg}$ p.o. daily. After 6 months, there was no improvement in proteinuria. AZA was replaced with CYC $150 \mathrm{mg}$ p.o. daily and prednisone $60 \mathrm{mg}$ p.o. daily. CYC therapy was complicated by leukopenia and hemorrhagic cystitis requiring discontinuation in September 2012. It was replaced with tacrolimus $4 \mathrm{mg}$ p.o. b.i.d. and he attained a complete remission in November 2013. Tacrolimus was stopped in February 2014 and prednisone discontinued in November 2014 after tapering. Serology did not correlate to renal response and MPO titers remained elevated in follow-up. Unfortunately, he has since been admitted for recurrent cocaine use, LCV, and septic shock secondary to a polymicrobial skin and soft tissue infection with bacteremia requiring skin grafting. He was last seen in follow-up in April 2015 with Cr $57 \mu \mathrm{mol} / \mathrm{L}$, eGFR $>60 \mathrm{~mL} / \mathrm{min} / 1.73 \mathrm{~m}^{2}$ and PCR $15.4 \mathrm{mg} / \mathrm{mmol}$ and has been $\mathrm{ab}-$ staining from cocaine.

\section{Conclusions}

We report 3 cases of AAV secondary to LAC with associated $\mathrm{MN}$ including 2 concurrent cases of AAV and $\mathrm{MN}$ secondary to LAC (cases 1,2$)$ and 1 case of $\mathrm{MN}$ with previous AAV secondary to LAC (case 3).

The association between $\mathrm{MN}$ and crescents is not a new clinical entity [24-26] and is thought to be due to immune complex injury, $\mathrm{MN}$ with superimposed AAV, or anti-glomerular basement disease. Nasr et al. [25] described 14 patients without systemic lupus erythematosus (SLE) or known secondary AAV with biopsy-proven MN and pauci-immune necrotizing AAV (32\% of which had crescents). The mean age was 58.7 years; acute kidney injury (AKI) and hematuria were frequent, and mean 24 -h urine proteinuria was $6.5 \mathrm{~g} /$ day. Seven were P-ANCA positive, 5 were C-ANCA positive, 1 had atypical ANCA, and there were $5 \mathrm{MPO}, 3 \mathrm{PR} 3$, and 1 mixed pattern. The majority were treated with CYC and corticosteroids with a relatively poor prognosis with $50 \%$ reaching ESRD or death. Although cocaine use was not explicitly reported, no patient had a syndrome compatible with LAC. It was thought that the 2 glomerular processes were unrelated occurring only by chance. Rodriguez et al. [26] reported 19 patients with biopsy-proven $\mathrm{MN}$ and crescents who were ANCA and anti-GBM negative without any clinical evidence of SLE. Mean age was 55 years, mean eGFR 39.7 $\mathrm{mL} / \mathrm{min} / 1.73 \mathrm{~m}^{2}$, proteinuria $11.5 \mathrm{~g} /$ day, $84 \%$ had hematuria, and $25 \%$ crescents. Fourteen patients were treated with immunosuppression and $21 \%$ progressed to ESRD with dialysis independent patients having a mean eGFR $53.3 \mathrm{~mL} / \mathrm{min} / 1.73 \mathrm{~m}^{2}$ and proteinuria $3.2 \mathrm{~g} /$ day. Six of 16 patients (38\%) were anti-PLA2R staining positive [27, 28] suggesting primary $\mathrm{MN}$ and 2 patients developed $\mathrm{MPO}$ positivity in follow-up. Zou et al. [29] reported the largest retrospective series of biopsy-proven AAV with $\mathrm{MN}$ from China with $223 \mathrm{AAV}$ patients of which 27 had combined $\mathrm{AAV}$ and $\mathrm{MN}$ and 30 matched primary $\mathrm{MN}$ controls. AAV with MN was associated with higher disease activity, Cr, proteinuria, nephrotic syndrome, ENT involvement but lower gross hematuria and overall worse renal survival at 1 year with varying pathology scores. In the cases in which it was measured, serum anti-PLA2R was present in 12.5 vs. $65 \%, p=0.028$, and glomerular staining in 6.6 vs. $66.6 \%, p=0.015$ in the combined AAV plus MN and $\mathrm{MN}$ control groups respectively.

In the 2000s, levamisole was identified as a cocaine adulterant (a pharmacologically active substance added to a drug in order to decrease the purity of the primary product without making the user aware) and is seen commonly worldwide $[17,18]$. Levamisole was previously used as an immunomodulatory agent and as adjuvant chemotherapy, but is no longer used due to its toxicity [30-32]. As an adulterant, it is associated with AAV with renal involvement $[22,33]$. As a secondary AAV, p-ANCA is more common than c-ANCA, and MPO more common than PR3 (although dual positivity may occur), with anti-phospholipid antibodies occasionally coexisting [16]. However, renal involvement by AAV is rare with a literature review revealing only 1 case of pauci-immune necrotizing and crescentic GN in 2011 [16]. $\mathrm{McGrath}$ et al. [22] reported the largest series of LACassociated AAV including 18 patients with complete clinical and laboratory data (eliminating 12 others) from a total of 327 patients with new positive ANCA serology between 2009 and 2010 at Massachusetts General Hospital. Arthralgias, skin (LCV, TMA, panniculitis, necrosis), and head/neck involvement were common. Renal involvement was less common and was found in 8 patients with abnormal urinalyses (proteinuria, hematuria, red blood cell casts) and 2 patients with AKI (Cr 7.7, $5.6 \mathrm{mg} /$ $\mathrm{dL}$ ). Only 1 patient had a renal biopsy performed and did not have any evidence of MN. p-ANCA and MPO serology were positive in all patients and c-ANCA and PR3 were positive in $50 \%$ and both were generally in high titers in conjunction with other autoimmune serology. 
There have been 3 previous case reports of $\mathrm{MN}$ in the setting of AAV presumably secondary to LAC but none confirmed levamisole exposure (online suppl. Table S1, see www.karger.com/doi/10.1159/000456553).

The pathogenesis of MN in the setting of LAC AAV is unclear. Induction of ANCA is thought to be due to an inflammatory event with an immune response against epitopes [34] of neutrophil granules influenced by genetic susceptibility [35] and environmental factors with neutrophil priming, epitope spreading and apoptosis with release of NETs [36] leading to vascular necrotizing inflammation, hemorrhage, and fibrin deposition [37]. Crescent formation occurs as a result of GBM injury and disruption leading to podocyte activation [38], cellular proliferation in Bowman's space with an infiltrate composed of monocytes, macrophages, parietal epithelial cells evolving to $\mathrm{T}$ cells and sclerosis. ANCA are predominantly IgG1 and IgG4 [39] and may lead to IC deposition detected by IF or EM in AAV [40] but is usually minimal $(<2+$ or "pauci-immune") with predominantly mesangial and rarely subepithelial deposits [40-42]. MN involves IgG antibodies against endogenous podocyte antigens or circulating IgG antibodies against antigens that are filtered across the GBM resulting in subepithelial immune deposits, complement activation, and diffuse granular IgG and C3 GBM staining and expansion. Primary MN is associated with IgG4 deposition while secondary $\mathrm{MN}$ is associated with IgG3 deposition in addition to mesangial deposits. Anti-PLA2R antibodies are thought to be the mechanism of injury in primary $\mathrm{MN}$ [43] with other antigens implicated including thrombospondin type I domain containing 7A [44] as well with etiology-specific antigens playing a role in secondary causes.

In AAV, ANCA may target endogenous podocyte antigens or lead to GBM injury and IC deposition along the

We were able to confirm exposure to LAC unlike other previous reports $[22,33,48-50]$ with all of our cases having compatible LAC AAV syndromes. Garg et al. [51] did report positive testing for LAC but the pathology was consistent with an immune complex GN rather than AAV with MN. Limitations of our cases include antiPLA2R testing only case 1 (although not a standard clinical practice at the time of cases 2 and 3 ) but we are confident in our exclusion of traditional secondary MN etiologies despite NSAID exposure in case 1 . We are confident in our description of this association and hope that it informs clinicians who might encounter it but ultimately cannot definitively prove causality.

\section{Authors' Contributions}

D.C. acquired the data and was a major contributor in writing the manuscript. D.C., C.S., K.R., M.K., K.B., and I.W.G. contributed to the conception of the study and revision of the manuscript. I.W.G. performed histological examination of the kidney. All authors read and approved the final manuscript.

\section{Acknowledgments}

We would like to thank Curtis Oleschuk, PhD, FCACB for his assistance from a clinical biochemistry perspective.

\section{Disclosure Statement}

The authors declare that they have no conflicts of interests. GBM, leading to cryptic podocyte neoepitopes that could contribute to an immune response resulting in coexisting MN. MPO, for example, has been shown to co-localize with IgG and C3 along anionic glomerular capillary walls in crescentic AAV with MN $[45,46]$. However, any significant injury to the GBM theoretically would result in significant pan-glomerular IC which would not be typically seen [40]. But what is it about levamisole that may potentiate whatever the underlying mechanism? It is known that LAC may contribute to the development on ANCA by inducing endothelial injury and the release of NET [47] so perhaps this vascular injury is implicated. Levamisole itself may actually be the antigen that induces $\mathrm{MN}$ but this remains to be proven with limited ultrastructural renal biopsy studies in the LAC [48].
References

Am J Nephrol 2017;45:209-216 DOI: $10.1159 / 000456553$
Collister/Sathianathan/Ryz/Karpinski/ Bernstein/Gibson
1 Friend K, Milone MC, Perrone J: Hyponatremia associated with levamisole-adulterated cocaine use in emergency department patients. Ann Emerg Med 2012;60:94-96.

2 Brecklin CS, Gopaniuk-Folga A, Kravetz T, Sabah S, Singh A, Arruda JA, Dunea G: Prevalence of hypertension in chronic cocaine users. Am J Hypertens 1998;11(11 pt 1):12791283.

3 Roth D, Alarcon FJ, Fernandez JA, Preston RA, Bourgoignie JJ: Acute rhabdomyolysis associated with cocaine intoxication. $\mathrm{N}$ Engl Med 1988;319:673-677.

4 Volcy J, Nzerue CM, Oderinde A, Hewan-Iowe $\mathrm{K}$ : Cocaine-induced acute renal failure, hemolysis, and thrombocytopenia mimicking thrombotic thrombocytopenic purpura. Am J Kidney Dis 2000;35:E3.

5 Madhrira MM, Mohan S, Markowitz GS, Pogue VA, Cheng JT: Acute bilateral renal infarction secondary to cocaine-induced vasospasm. Kidney Int 2009;76:576-580. 
6 Zoghby Z, Sekhon IS, Miller DV, Sethi S: Cocaine, loin pain, and renal vein thrombosis. Am J Kidney Dis 2007;49:859-861.

7 Wojciechowski D, Kallakury B, Nouri P: A case of cocaine-induced acute interstitial nephritis. Am J Kidney Dis 2008;52:792-795.

8 Tan AU Jr, Cohen AH, Levine BS: Renal amyloidosis in a drug abuser. J Am Soc Nephrol 1995;5:1653-1658.

9 Fogo A, Superdock KR, Atkinson JB: Severe arteriosclerosis in the kidney of a cocaine addict. Am J Kidney Dis 1992;20:513-515.

10 van der Woude FJ, Waldherr R: Severe renal arterio-arteriolosclerosis after cocaine use. Nephrol Dial Transplant 1999;14:434-435.

11 Fine DM, Garg N, Haas M, Rahman MH, Lucas GM, Scheel PJ, Atta MG: Cocaine use and hypertensive renal changes in HIV-infected individuals. Clin J Am Soc Nephrol 2007;2: 1125-1130.

12 Perneger TV, Klag MJ, Whelton PK: Recreational drug use: a neglected risk factor for end-stage renal disease. Am J Kidney Dis 2001;38:49-56.

13 Vupputuri S, Batuman V, Muntner P, Bazzano LA, Lefante JJ, Whelton PK, He J: The risk for mild kidney function decline associated with illicit drug use among hypertensive men. Am J Kidney Dis 2004;43:629-635.

14 Buettner M, Toennes SW, Buettner S, Bickel M, Allwinn R, Geiger H, Bratzke H, Amann $\mathrm{K}$, Jung O: Nephropathy in illicit drug abusers: a postmortem analysis. Am J Kidney Dis 2014;63:945-953.

15 Norris KC, Thornhill-Joynes M, Robinson C, Strickland T, Alperson BL, Witana SC, Ward $\mathrm{HJ}$ : Cocaine use, hypertension, and end-stage renal disease. Am J Kidney Dis 2001;38:523528.

16 Larocque A, Hoffman RS: Levamisole in cocaine: unexpected news from an old acquaintance. Clin Toxicol (Phila) 2012;50:231-241.

17 Buchanan JA, Heard K, Burbach C, Wilson ML, Dart R: Prevalence of levamisole in urine toxicology screens positive for cocaine in an inner-city hospital. JAMA 2011;305:16571658.

18 Eiden C, Peyriere H, Diot C, Mathieu O: Prevalence of levamisole and aminorex in patients tested positive for cocaine in a French University Hospital. Clin Toxicol (Phila) 2015;53: 604-608.

19 Zhu NY, Legatt DF, Turner AR: Agranulocytosis after consumption of cocaine adulterated with levamisole. Ann Intern Med 2009; 150:287-289.

20 Ullrich K, Koval R, Koval E, Bapoje S, Hirsh JM: Five consecutive cases of a cutaneous vasculopathy in users of levamisole-adulterated cocaine. J Clin Rheumatol 2011;17:193-196.

21 Zwang NA, Van Wagner LB, Rose S: A case of levamisole-induced systemic vasculitis and cocaine-induced midline destructive lesion: a case report. J Clin Rheumatol 2011;17:197200.

22 McGrath MM, Isakova T, Rennke HG, Mottola AM, Laliberte KA, Niles JL: Contaminat- ed cocaine and antineutrophil cytoplasmic antibody-associated disease. Clin J Am Soc Nephrol 2011;6:2799-2805.

23 Hoxha E, Kneissler U, Stege G, Zahner G, Thiele I, Panzer U, Harendza S, Helmchen UM, Stahl RA: Enhanced expression of the Mtype phospholipase A2 receptor in glomeruli correlates with serum receptor antibodies in primary membranous nephropathy. Kidney Int 2012;82:797-804.

24 Tse WY, Howie AJ, Adu D, Savage CO, Richards NT, Wheeler DC, Michael J: Association of vasculitic glomerulonephritis with membranous nephropathy: a report of 10 cases. Nephrol Dial Transplant 1997;12:1017-1027.

25 Nasr SH, Said SM, Valeri AM, Stokes MB, Masani NN, D’Agati VD, Markowitz GS: Membranous glomerulonephritis with ANCA-associated necrotizing and crescentic glomerulonephritis. Clin J Am Soc Nephrol 2009;4:299-308.

26 Rodriguez EF, Nasr SH, Larsen CP, Sethi S, Fidler ME, Cornell LD: Membranous nephropathy with crescents: a series of 19 cases. Am J Kidney Dis 2014;64:66-73.

27 Hoxha E, Kneissler U, Stege G, Zahner G, Thiele I, Panzer U, Harendza S, Helmchen UM, Stahl RA: Enhanced expression of the Mtype phospholipase A2 receptor in glomeruli correlates with serum receptor antibodies in primary membranous nephropathy. Kidney Int 2012;82:797-804

28 Larsen CP, Messias NC, Silva FG, Messias E, Walker PD: Determination of primary versus secondary membranous glomerulopathy utilizing phospholipase A2 receptor staining in renal biopsies. Mod Pathol 2013;26:709-715.

29 Zou R, Liu G, Cui Z, Chen M, Zhao MH: Clinical and immunologic characteristics of patients with ANCA-associated glomerulonephritis combined with membranous nephropathy: a retrospective cohort study in a single Chinese center. Medicine (Baltimore) 2015;94:e1472.

30 Scheinberg MA, Bezerra JB, Almeida FA, Silveira LA: Cutaneous necrotising vasculitis induced by levamisole. Br Med J 1978;1:408.

31 Hansen TM, Petersen J, Halberg P, Permin H, Ullman S, Brun C, Larsen S: Levamisole-induced nephropathy. Lancet 1978;2(8092 pt 1): 737.

32 Shearn MA, Tu WH: Proliferative glomerulonephritis associated with levamisole therapy of rheumatoid arthritis. J Rheumatol 1981;8: 522-523.

33 Carlson AQ, Tuot DS, Jen KY, Butcher B, Graf J, Sam R, Imboden JB: Pauci-immune glomerulonephritis in individuals with disease associated with levamisole-adulterated cocaine: a series of 4 cases. Medicine (Baltimore) 2014;93:290-297.

34 Roth AJ, Ooi JD, Hess JJ, van Timmeren MM, Berg EA, Poulton CE, McGregor J, Burkart M, Hogan SL, Hu Y, Winnik W, Nachman PH, Stegeman CA, Niles J, Heeringa P, Kitching AR, Holdsworth S, Jennette JC, Preston GA, Falk RJ: Epitope specificity determines patho- genicity and detectability in ANCA-associated vasculitis. J Clin Invest 2013;123:17731783.

35 Lyons PA, Rayner TF, Trivedi S, Holle JU, Watts RA, Jayne DR, Baslund B, Brenchley P, Bruchfeld A, Chaudhry AN, Cohen Tervaert JW, Deloukas P, Feighery C, Gross WL, Guillevin L, Gunnarsson I, Harper L, Hruskova Z, Little MA, Martorana D, Neumann T, Ohlsson S, Padmanabhan S, Pusey CD, Salama AD, Sanders JS, Savage CO, Segelmark M, Stegeman CA, Tesar V, Vaglio A, Wieczorek S, Wilde B, Zwerina J, Rees AJ, Clayton DG, Smith KG: Genetically distinct subsets within ANCA-associated vasculitis. N Engl J Med 2012;367:214-223.

36 Kessenbrock K, Krumbholz M, Schonermarck U, Back W, Gross WL, Werb Z, Grone HJ, Brinkmann V, Jenne DE: Netting neutrophils in autoimmune small-vessel vasculitis. Nat Med 2009;15:623-625.

37 Jennette JC, Xiao H, Falk RJ: Pathogenesis of vascular inflammation by anti-neutrophil cytoplasmic antibodies. J Am Soc Nephrol 2006; 17:1235-1242.

38 Thorner PS, Ho M, Eremina V, Sado Y, Quaggin S: Podocytes contribute to the formation of glomerular crescents. J Am Soc Nephrol 2008;19:495-502.

39 Segelmark M, Wieslander J: IgG subclasses of antineutrophil cytoplasm autoantibodies (ANCA). Nephrol Dial Transplant 1993;8: 696-702.

40 Haas M, Eustace JA: Immune complex deposits in ANCA-associated crescentic glomerulonephritis: a study of 126 cases. Kidney Int 2004;65:2145-2152.

41 Neumann I, Regele H, Kain R, Birck R, Meis FT: Glomerular immune deposits are associated with increased proteinuria in patients with ANCA-associated crescentic nephritis. Nephrol Dial Transplant 2003;18:524-531.

42 Vizjak A, Rott T, Koselj-Kajtna M, Rozman B, Kaplan-Pavlovcic S, Ferluga D: Histologic and immunohistologic study and clinical presentation of ANCA-associated glomerulonephritis with correlation to ANCA antigen specificity. Am J Kidney Dis 2003;41:539-549.

43 Beck LH Jr, Bonegio RG, Lambeau G, Beck DM, Powell DW, Cummins TD, Klein JB, Salant DJ: M-type phospholipase A2 receptor as target antigen in idiopathic membranous nephropathy. N Engl J Med 2009;361:11-21.

44 Tomas NM, Beck LH Jr, Meyer-Schwesinger C, Seitz-Polski B, Ma H, Zahner G, Dolla G, Hoxha E, Helmchen U, Dabert-Gay AS, Debayle D, Merchant M, Klein J, Salant DJ, Stahl RA, Lambeau G: Thrombospondin type-1 domain-containing 7A in idiopathic membranous nephropathy. N Engl J Med 2014;371: 2277-2287.

45 Matsumoto K, Honda H, Shibata T, Sanada D, Wada Y, Ashikaga E, Kuroki A, Kitazawa K, Akizawa T: MPO-ANCA crescentic glomerulonephritis complicated by membranous nephropathy: MPO demonstrated in epimembranous deposits. NDT Plus 2009;2:461-465. 
46 Hanamura K, Tojo A, Kinugasa S, Asaba K, Onozato ML, Uozaki H, Fukayama M, Fujita T: Detection of myeloperoxidase in membranous nephropathy-like deposits in patients with anti-neutrophil cytoplasmic antibodyassociated glomerulonephritis. Hum Pathol 2011;42:649-658.

47 Lood C, Hughes GC: Neutrophil extracellular traps as a potential source of autoantigen in cocaine-associated autoimmunity. Rheumatology (Oxford) 2016;pii:kew256.
48 Liu YW, Mutnuri S, Siddiqui SB, Weikle GR, Oladipo O, Ganti N, Beach RE, Afrouzian M: Levamisole-adulterated cocaine nephrotoxicity: ultrastructural features. Am J Clin Pathol 2016;145:720-726.

49 Carrara C, Emili S, Lin M, Alpers CE: Necrotizing and crescentic glomerulonephritis with membranous nephropathy in a patient exposed to levamisole-adulterated cocaine. Clin Kidney J 2016;9:234-238.
50 Roca-Argente L, Moll-Guillen JL, Espi-Reig J, Blanes-Julia M, Garcia-Martinez AM, PujolMarco C, Hernandez-Jaras J: Membranous glomerulonephritis and cellular crescents induced by levamisole-adulterated cocaine abuse: a case report. Ann Transl Med 2015;3: 271.

51 Garg L, Gupta S, Swami A, Zhang P: Levamisole/cocaine induced systemic vasculitis and immune complex glomerulonephritis. Case Rep Nephrol 2015;2015:372413. 